\title{
Hepatic NF-kB-inducing Kinase (NIK) Suppresses Liver Regeneration in Chronic Liver
}

\section{Disease}

\author{
Yi Xiong ${ }^{1 \S}$, Adriana Souza Torsoni ${ }^{1,2 \S}$, Feihua Wu ${ }^{1,3}$, Hong Shen ${ }^{1}$, Yan Liu ${ }^{1}$, Mark J Canet ${ }^{1}$, \\ Yatrik M. Shah ${ }^{1}$, M. Bishr Omary ${ }^{1}$, Yong Liu ${ }^{4}$, Liangyou Rui ${ }^{1,5^{*}}$ \\ ${ }^{1}$ Department of Molecular \& Integrative Physiology, ${ }^{5}$ Department of Internal Medicine, \\ University of Michigan Medical School, Ann Arbor, MI 48109, USA
}
${ }^{2}$ Laboratory of Metabolic Disorders, School of Applied Sciences, University of Campinas, Limeira, São Paulo, Brazil
${ }^{3}$ Department of Pharmacology of Chinese Materia Medica, School of Traditional Chinese Medicine, China Pharmaceutical University, Nanjing 211198, China

${ }^{4}$ College of Life Sciences, the Institute for Advanced Studies, Wuhan University, Wuhan 2 430072, China

Keywords: Liver regeneration, hepatocyte proliferation, chronic liver disease, NF- $\kappa$ B-inducing Kinase, IKK $\alpha$, JAK2, STAT3, interleukin 6

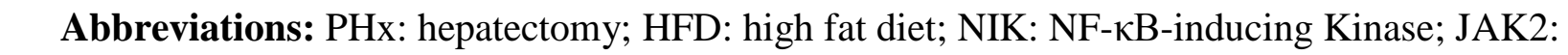

Janus kinase 2; STAT3: Signal transducer and activator of transcription 3; AAF: 2-

7 acetylaminofluorence.

8 Disclosure statement: All authors have nothing to declare.

*Lead Contact and corresponding author:

Liangyou Rui, Ph.D., Department of Molecular \& Integrative Physiology, University of

1 Michigan Medical School, Ann Arbor, MI 48109, USA. E-mail: ruily@umich.edu.

Footnotes: §co-first authors: Yi Xiong and Adriana Souza Torsoni. 


\section{Summary}

25 liver disease, promoting disease progression. Herein, we have identified NF-kB-inducing kinase

26 (NIK) as an unrecognized suppressor of hepatocyte replication. Hepatic NIK was aberrantly

27 activated in chronic liver disease. Hepatocyte-specific deletion of $N I K$ or its downstream

28 mediator $I K K \alpha$ substantially accelerated hepatocyte proliferation and liver regeneration

29 following partial hepatectomy. Mechanistically, NIK and IKK $\alpha$ suppressed the mitogenic

30 JAK2/STAT3 pathway, thereby inhibiting hepatocyte cell cycle progression. Remarkably,

31 inactivation of hepatic NIK largely reversed suppression of the hepatic JAK2/STAT3 pathway,

32 hepatocyte replication, and liver regeneration induced by either chronic liver injury or metabolic

33 stress. Our data suggest that hepatic NIK acts as a rheostat for liver regeneration to restrain liver

34 overgrowth. Pathologic activation of hepatic NIK blocks hepatocyte replication, likely

35 contributing to liver disease progression. 


\section{Introduction}

The liver is an essential metabolic organ, and often experiences metabolic stress during

fasting and feeding and in overnutrition states (Rui, 2014). It is also frequently exposed to

harmful insults, because it detoxifies endogenous and exogenous hepatotoxic substances. Dietary

41 hepatotoxins and gut microbiota-derived toxic substances are transported directly to the liver

42 through enterohepatic circulation, further increasing risk for liver injury. To compensate for a

43 loss of hepatocytes, the liver has a powerful regenerative capability to maintain its homeostasis

44 and integrity (Michalopoulos, 2017). After $70 \%$ of partial hepatectomy (PHx), rodents are able to

45 regain their normal liver mass within one week (Miyaoka et al., 2012). Notably, it is equally

46 important to avoid generation of aberrant liver cells from damaged hepatocytes in order to

47 maintain liver integrity. Thus, a quality control mechanism likely exists to block injured

48 hepatocytes from proliferating. We speculate that hepatocellular stress and/or injury signals

49 activate hepatocyte-intrinsic sensors that in turn block proliferation of damaged hepatocytes

50 through this putative quality control system.

Reparative hepatocyte proliferation is severely impaired in chronic liver disease,

52 including nonalcoholic fatty liver disease (NAFLD), alcoholic liver disease, and a chronic

53 exposure to hepatotoxins (Inaba et al., 2015; Michalopoulos, 2013; Richardson et al., 2007;

54 Sancho-Bru et al., 2012). Hepatocyte proliferative arrest is associated with liver inflammation,

55 injury, and fibrosis in patients with steatohepatitis (NASH) (Richardson et al., 2007), suggesting

56 that impaired hepatocyte replication exacerbates disease progression. Numerous factors have

57 been identified to promote hepatocyte proliferation, including various cytokines, growth factors,

and the JAK2/STAT3, MAPK, PI 3-kinase, and NF-kB pathways (Michalopoulos, 2017).

59 Paradoxically, most of these positive regulators are elevated in chronic liver disease. We reason 
that liver regeneration is also governed by negative regulators that function as a molecular rheostat to restrain liver overgrowth by counterbalancing positive regulators. Some of these negative regulators likely have dual functions and are involved in the quality control of liver regeneration by blocking proliferation of damaged hepatocytes. We postulate that in chronic

64 liver disease, such negative regulators are overactivated by hepatocellular stress/injury, leading to pathological suppression of hepatocyte proliferation/liver regeneration. However, negative regulators for hepatocyte replication, in contrast to extensively studied positive regulators, are

67 poorly understood. we identified NF-kB-inducing kinase (NIK). NIK is a Ser/Thr kinase known to activate the noncanonical NF-kB2 pathway (Sun, 2012). It phosphorylates and activates IKKa (Xiao et al.,

71 2001). IKK $\alpha$ phosphorylates NF-kB2 precursor $\mathrm{p} 100$, resulting in generation of a mature NF-

72 kB2 p52 form (Sun, 2012; Xiao et al., 2001). We reported that metabolic stress, oxidative stress,

73 hepatotoxins, and many cytokines all stimulate hepatic NIK (Jiang et al., 2015; Sheng et al., 74 2012). Consistently, hepatic NIK is aberrantly activated in both mice and humans with NAFLD,

75 alcoholic liver disease, or other types of chronic liver disease (Shen et al., 2014). Therefore, NIK

76 is involved in sensing of hepatocellular stress and damage, likely functioning as a hepatocyte-

77 intrinsic sensor for stress/injury. In this work, we characterized hepatocyte-specific NIK

$78\left(N I K^{\Delta h e p}\right)$ and $I K K \alpha\left(I K K \alpha^{\Delta h e p}\right)$ knockout mice, and examined reparative hepatocyte replication

79 using a PHx model. We found that the hepatic NIK/IKK $\alpha$ pathway suppresses reparative

80 hepatocyte proliferation and liver regeneration by inhibiting the JAK2/STAT3 pathway.

81 Aberrantly activated hepatic NIK in chronic liver disease is responsible for, in part, impairment 
82 in liver regeneration. Our data suggest that NIK is an unrecognized hepatocyte-intrinsic sensor for stress/injury and negative regulator of hepatocyte proliferation.

\section{Results} $N I K^{\text {Lhep }}$ mice were generated by crossing $N I K^{\text {floxflox }}$ mice with albumin-Cre drivers as described previously (Shen et al., 2017). Proliferating cells were detected by immunostaining liver sections with antibody against Ki67, a marker of proliferating cells (Fig. 1A). Liver proliferating rates were low $(<1 \%)$ under basal conditions and comparable between $N I K^{\Delta h e p}$ and $N I K^{\text {floxflox }}$ mice after PHx; remarkably, liver proliferating cells were $85 \%$ higher in $N I K^{\Delta h e p}$ mice relative to

$94 N I K^{f l o x}$ flox mice (Fig. 1B). In line with these findings, the number of liver $\mathrm{BrdU}^{+}$proliferating cell, as assessed by BrdU assays, was also much higher in $N I K^{\Delta h e p}$ than in $N I K^{\text {floxfllox }}$ mice (Fig. 1C). Liver cell proliferation declined $48 \mathrm{~h}$ after $\mathrm{PHx}$ in both $N I K^{\text {thep }}$ and $N I K^{\text {floxflox }}$ mice, and

97 became comparable between these two groups within $96 \mathrm{~h}$ after PHx (Fig. 1B). antibodies against either Ki67 and HNF4 $\alpha$ (a hepatocyte marker) or Ki67 and F4/80 (a Kupffer cell/macrophage marker). HNF $4 \alpha^{+}$hepatocytes accounted for $96 \%$ of liver $\mathrm{Ki} 67^{+}$proliferating cells in $N I K^{\text {thep }}$ mice $48 \mathrm{~h}$ after PHx (Figs. 1D and 1F), whereas F4/80+ Kupffer

102 cells/macrophages accounted for $<4 \%$ of $\mathrm{Ki} 67^{+}$cells (Fig. 1E-F). Together, these data indicate that NIK is an intrinsic suppressor of hepatocyte proliferation. 
Next, we examined the effect of NIK deficiency on hepatocyte death. The number of

105

106

107

108 liver TUNEL ${ }^{+}$apoptotic cells, as assessed by TUNEL assays, was slightly lower in $N I K^{\text {thep }}$ than in NIK floxfflox mice, but the difference was not statistically significant (Fig. 1G). Plasma alanine aminotransferase (ALT) activity, a liver injury index, was comparable between $N I K^{\text {thep }}$ and NIK $K^{\text {floxflox }}$ mice under both basal and PHx conditions (Fig. 1H). Thus, it is unlikely that hepatic NIK regulates hepatocyte death under these conditions.

To further validate the role of hepatic NIK in the maintenance of liver homeostasis, we quantified liver regeneration rates within $48 \mathrm{~h}$ after PHx. In line with increased hepatocyte proliferation, liver growth rates were also significantly increased in $N I K^{\text {thep }}$ mice compared with NIK $K^{\text {floxflox }}$ mice (Fig. 1I). In light of these findings, we propose that NIK is a hepatocyte-intrinsic rheostat for reparative proliferation that is involved in the maintenance of liver homeostasis and integrity. Moreover, damage-induced NIK activation likely provides a quality control mechanism to prevent generation of aberrant cells from damaged hepatocytes.

\section{The NF-kB1, MAPK, and PI 3-kinase pathways do not mediate NIK suppression of} hepatocyte reparative proliferation. To further confirm NIK inhibition of hepatic cell cycle progression, we measured the levels of hepatic cyclin D1, which is believed to drive hepatocyte proliferation after PHx (Michalopoulos, 2013). Hepatic cyclin D1 was undetectable under basal conditions in both $N I K^{\Delta h e p}$ and $N I K^{f l o x f l l o x}$ mice, and markedly increased after PHx in both groups (Fig. 2A). In line with increased hepatocyte proliferation, hepatic cyclin D1 levels were significantly higher in $N I K^{\text {thep }}$ than in $N I K^{\text {floxflox }}$ mice (Fig. 2A-B).

We next sought to study the molecular mechanism of NIK action. NF-kB1, MAPK, and PI 3-kinase pathways are known to be involved in mediating PHx-stimulated liver regeneration (Michalopoulos, 2013; Pauta et al., 2016; Wuestefeld et al., 2013). Surprisingly, phosphorylation 
127 of hepatic IKK $\alpha / \beta, \mathrm{IkB} \alpha, \mathrm{p} 65$ (the NF-kB1 pathway), Akt (pSer473) (the PI 3-kinase pathway),

128 ERK1/2, and JNK (the MAPK pathway) was comparable between NIK $K^{\Delta h e p}$ and $N I K^{\text {floxflox }}$ mice 4

$129 \mathrm{~h}$ after PHx (Fig. 2C). We also assessed liver reactive oxygen species (ROS) and expression of

130 various cytokines, and did not detect difference between $N I K^{\Delta h e p}$ and $N I K^{\text {floxflox }}$ mice (Fig. 2D-E).

131 Therefore, these pathways are unlikely to mediate suppression of liver regeneration by hepatic

132 NIK.

NIK directly suppresses the Janus kinase 2 (JAK2)/STAT3 pathway. JAK2

134 phosphorylates and activates STAT3, and the JAK2/STAT3 pathway is believed to drive

135 hepatocyte proliferation (Shi et al., 2017; Wang et al., 2011). We postulated that NIK might

136 suppresses hepatocyte proliferation by inhibiting the JAK2/STAT3 pathway. Liver extracts were

137 prepared $4 \mathrm{~h}$ after PHx and immunoblotted with anti-phospho-JAK2 (pTyr1007/1008) or anti-

138 phospho-STAT3 (pTyr705) antibodies. Phosphorylation of both JAK2 and STAT3 was

139 significantly higher in $N I K^{\text {thep }}$ than in $N I K^{\text {floxflox }}$ littermates (Fig. 3A).

To confirm that NIK directly inhibits the JAK2/STAT3 pathway, we transiently coexpressed JAK2 and STAT3 with NIK in HEK293 cells. JAK2 was autophosphorylated and robustly phosphorylated STAT3 in the absence of NIK (Fig. 3B), as we previously reported (Rui and Carter-Su, 1999). Overexpression of NIK dramatically attenuated phosphorylation of both JAK2 and STAT3 (Fig. 3B). Moreover, NIK was coimmunoprecipitated with JAK2 (Fig. 3C).

145 These data indicate that NIK binds to JAK2 and inhibits JAK2 activity, thereby suppressing the JAK2/STAT3 pathway. reparative proliferation (Cressman et al., 1996; Riehle et al., 2008). Mouse primary hepatocytes 
150

151

152

153

154

155

156

157

158

159

160

161

162

163

164

165

166

167

168

169

170

171

172

were transduced with NIK or $\beta$-galactosidase ( $\beta$-gal; control) adenoviral vectors, and then stimulated with IL6. IL6 rapidly and robustly stimulated phosphorylation of STAT3 in $\beta$-galtransduced hepatocytes; strikingly, overexpression of NIK completely blocked IL6-stimulated phosphorylation of STAT3 (Fig. 3D). We did not detect endogenous JAK2, because its levels were below the detection threshold of our assays. Overall, our data unveiled unrecognized crosstalk between NIK and JAK2/STAT3 pathways. NIK inhibits hepatocyte proliferation at least in part by restraining the JAK2/STAT3 pathway.

Hepatic IKKa suppresses liver regeneration after PHx. NIK phosphorylates and activates IKK $\alpha$ (Sun, 2012), prompting us to test if hepatocyte-specific IKK $\alpha$ knockout mice, like $N I K^{\Delta h e p}$ mice, also display accelerated liver regeneration. $I K K \alpha^{\text {thep }}$ mice were generated by crossing IKK $\alpha^{\text {floxflox }}$ mice with albumin-Cre drivers (Liu et al., 2008). IKK $\alpha$ was disrupted specifically in the liver, but not the brain, heart, kidney, skeletal muscle, and spleen, of $I K K \alpha^{\Delta h e p}$ mice (Fig. 4A). We performed PHx on $I K K \alpha^{\text {floxfflox }}$ and $I K K \alpha^{\text {thep }}$ male mice at 8-9 weeks of age. The number of liver $\mathrm{Ki}_{67^{+}}$proliferating cell was significantly higher in $I K K \alpha^{\Delta h e p}$ than in $I K K \alpha^{\text {floxflox }}$ littermates $48 \mathrm{~h}$ after PHx (Fig. 4B). The proliferating cells were HNF4 $\alpha^{+}$ hepatocytes (Fig. 4C). Consistently, liver cyclin D1 levels were significantly higher in IKK $\alpha^{\text {thep }}$ than in $I K K \alpha^{\text {flox/flox }}$ mice (Fig. 4D). In contrast, liver cell death was comparable between $I K K \alpha^{\Delta h e p}$ and $I K K \alpha^{\text {floxfflox }}$ littermates (Fig. 4E). Consequently, liver regeneration rates were significantly higher in $I K K \alpha^{\Delta h e p}$ mice relative to $I K K \alpha^{\text {floxfflox }}$ mice (Fig. 4F). These results suggest that IKK $\alpha$ acts downstream of NIK to suppress liver regeneration.

We next sought to test if IKK $\alpha$, like NIK, inhibits the JAK2/STAT3 pathway. Phosphorylation of both JAK2 and STAT3 was significantly higher in $I K K \alpha^{\text {thep }}$ than in $I K K \alpha^{\text {floxfllox }}$ mice $4 \mathrm{~h}$ after PHx (Fig. 5A-B). To determine whether IKK $\alpha$ directly inhibits JAK2, 
IKK $\alpha$ was transiently coexpressed with JAK2 in HEK293 cells. IKK $\alpha$ markedly decreased JAK2 autophosphorylation and the ability of JAK2 to phosphorylate STAT3 (Fig. 5C). Furthermore, IKK $\alpha$ was coimmunoprecipitated with JAK2 (Fig. 5D). Thus, NIK is able to inhibit the JAK2/STAT3 pathway both directly and indirectly through activating IKK $\alpha$.

\section{Deletion of hepatic NIK reverses hepatotoxin-induced suppression of liver}

regeneration. Since hepatic NIK is aberrantly activated in chronic liver disease (Shen et al., 2014; Sheng et al., 2012), we speculated that it might be a causal factor for impaired liver regeneration that promotes disease progression. To model chronic liver disease, mice were treated with 2-acetylaminofluorene (AAF), a hepatotoxin (Laishes and Rolfe, 1981). AAF treatment considerably activated hepatic NIK, as assessed by upregulation of NF-kB2 p52 (Fig. 6A). To examine the impact of elevated NIK on liver regeneration, $N I K^{\text {Shep }}$ and $N I K^{\text {floxflox }}$ mice were pretreated with AAF for 10 days prior to PHx. Proliferating cells were assessed $48 \mathrm{~h}$ after PHx by immunostaining liver sections with anti-Ki67 antibody (Fig. 6B). Baseline hepatocyte proliferation was low and similar between $N I K^{\text {floxflox }}$ and $N I K^{\Delta h e p}$ mice prior to PHx (Fig. 6C).

PHx markedly increased hepatocyte proliferation in PBS-treated $N I K^{\text {floxflox }}$ mice (control) as expected, and AAF pretreatment substantially decreased hepatocyte proliferation by $>50 \%$ (Fig. 6D). Remarkably, deletion of hepatic NIK largely reversed AAF-induced suppression of hepatocyte proliferation in $N I K^{\Delta h e p}$ mice (Fig. 6D). In contrast, plasma ALT levels (a liver injury index) was similar between $N I K^{\text {floxflox }}$ and $N I K^{\text {thep }}$ mice (Fig. 6E). In line with increased hepatocyte proliferation, liver regeneration rates after $\mathrm{PHx}$ were also significantly higher in AAF-pretreated $N I K^{\Delta h e p}$ mice relative to $N I K^{\text {floxflox }}$ littermates (Fig. 6F).

We next examined cell signaling events that drive cell cycle progression. We detected baseline phosphorylation of hepatic STAT3 in AAF-pretreated NIK ${ }^{\text {Ahep }}$ but not $N I K^{\text {floxflox }}$ mice 
196

197

198

199

200

201

202

203

204

205

206

207

208

209

210

211

212

213

214

215

216

217

218

prior to PHx (Fig. 6G). PHx stimulated phosphorylation of hepatic STAT3 in both NIK $K^{\Delta h e p}$ and NIK ${ }^{\text {floxfflox }}$ mice; however, STAT3 phosphorylation was substantially higher in NIK ${ }^{\text {Lhep }}$ mice (Fig. 6G). Baseline hepatic cyclin D was undetectable in both AAF-pretreated $N I K^{\Delta h e p}$ and $N I K^{\text {floxflox }}$ mice prior to PHx. PHx upregulated hepatic cyclin D1 to a higher level in $N I K^{\Delta h e p}$ mice relative to NIK floxflox littermates (Fig. 6G). Together, these data further support the notion that NIK serves as a hepatocyte-intrinsic rheostat to restrain liver regeneration through inhibiting the JAK2/STAT3 pathway. Importantly, abnormal activation of hepatic NIK is likely responsible for impaired liver regeneration in chronic liver disease, contributing to disease progression.

\section{Deletion of hepatic NIK reverses NAFLD-associated suppression of liver}

regeneration. To model NAFLD, NIK $K^{\Delta h e p}$ and $N I K^{\text {floxflox }}$ mice were fed a high fat diet (HFD) for 10 weeks. HFD-fed $N I K^{\Delta h e p}$ and $N I K^{\text {floxfflox }}$ mice developed liver steatosis, as assessed by liver triacylglycerol (TAG) levels, to a similar degree (Fig. 7A). HFD feeding was reported to increase hepatic NIK activity (Sheng et al., 2012). Consistently, NF-kB2 p52 levels was higher in HFDfed than normal chow-fed mice (Fig. 7B).

NAFLD/NASH is associated with impaired liver regeneration (Collin de l'Hortet et al., 2014; Inaba et al., 2015). We hypothesized that elevated hepatic NIK is responsible for suppression of liver generation in NAFLD/NASH. NIK $K^{\Delta h e p}$ and $N I K^{\text {floxflox }}$ mice were fed a HFD for 10 weeks followed by PHx. Hepatocyte proliferation was assessed $48 \mathrm{~h}$ post-PHx by staining liver sections with anti-Ki67 antibody (Fig. 7C). Baseline hepatocyte proliferation was similarly low in both $N I K^{\Delta h e p}$ and $N I K^{\text {floxfflox }}$ mice prior to PHx (Fig. 7D). PHx markedly induced hepatocyte proliferation in chow-fed $N I K^{\text {floxflox }}$ mice, and HFD feeding substantially decreased $\mathrm{Ki}^{+} 7^{+}$proliferating hepatocyte number as expected (Fig. 7E). Remarkably, hepatocyte-specific deletion of $N I K$ dramatically increased $\mathrm{Ki} 67^{+}$liver cell number in $N I K^{\Delta h e p}$ mice close to normal 
219 levels (Fig. 7E). Consistently, liver growth rates was higher in $N I K^{\Delta h e p}$ mice relative to $N I K^{\text {flox/flox }}$

220 mice, albeit those differences were not statistically significant (Fig. 7F). It is worth mentioning

221 that high levels of liver TAG in HFD-fed mice might mask our assessments of liver growth rates

222 that were based on liver weight changes. Plasma ALT levels were comparable between NIK ${ }^{\text {thep }}$

223 and $N I K^{\text {floxfflox }}$ littermates under both basal and PHx conditions (Fig. 7G), suggesting that hepatic

224 NIK does not directly affect liver injury under these conditions.

We further explored mitogenic pathways in the livers of these mice. STAT3

226 phosphorylation was similar between HFD-fed $N I K^{\Delta h e p}$ and $N I K^{f l o x}$ flox mice under baseline

227 conditions, and increased to a considerably higher level in NIK ${ }^{\text {thep }}$ mice relative to NIK floxflox

228 mice 48 h post-PHx (Fig. 7H). Hepatic cyclin D1 levels were also higher in NIK ${ }^{\Delta h e p}$ mice relative 229 to NIK flox/flox mice after PHx (Fig. 7H). Overall, these data suggest that aberrant activation of 230 hepatic NIK in NAFLD/NASH suppresses hepatocyte reparative proliferation through inhibiting 231 the JAK2/STAT3 pathway.

\section{Discussion} hepatocytes, thereby maintaining liver homeostasis and integrity. The quality control mechanism of liver regeneration likely blocks proliferation of damaged hepatocytes, preventing generation

236 of dysfunctional or aberrant cells from the impaired hepatocytes. In this work, we have identified

237 NIK as a hepatocyte-intrinsic sensor for liver stress and injury that controls the quality control 238 machinery. Supporting this notion, we found that metabolic stress and numerous hepatotoxic 239 stimuli potently activate hepatic NIK (Sheng et al., 2012). Hepatocyte-specific deletion of NIK, 240 which is expected allow damaged hepatocytes to regain their proliferating capability due to 
241 disruption of their quality control mechanism, substantially increases hepatocyte proliferation

242 and accelerates liver regeneration in $N I K^{\Delta h e p}$ mice following PHx.

We have gained important insight into the potential molecular mechanism by which NIK suppresses hepatocyte proliferation and liver regeneration. NIK is known to activate IKK $\alpha$ (Sun, 2012). We found that mice with hepatocyte-specific deletion of $I K K \alpha$ phenocopy $N I K^{\Delta h e p}$ mice with regard to reparative hepatocyte proliferation and liver regeneration following PHx. It is well established that activation of the JAK2/STAT3 drives hepatocyte proliferation and liver regeneration (Cressman et al., 1996; Riehle et al., 2008; Shi et al., 2017; Wang et al., 2011). suppression of liver regeneration by NIK. 
AAF or a HFD. In these contexts, we postulate that hepatic NIK serves as a rheostat for liver regeneration to counterbalance overgrowth of the liver. Thus, aberrant activation of hepatic NIK is expected to impair reparative hepatocyte proliferation, contributing to liver disease

267 progression. Supporting this notion, we found that hepatocyte-specific inactivation of NIK

268 substantially increases hepatocyte proliferation in both AAF-treated or HFD-fed NIK ${ }^{\Delta h e p}$ mice

269 following PHx. Consistently, both phosphorylation of hepatic JAK2 and STAT3 and expression

270 of hepatic cyclin D1 are markedly elevated in NIK ${ }^{\text {thep }}$ mice. These findings raise an intriguing

271 possibility that pharmacological inhibition of hepatic NIK may provide a novel therapeutic

272 strategy to treat chronic liver disease.

In conclusion, we have identified hepatic NIK as an unrecognized hepatocyte-intrinsic sensor for hepatic stress/injury that suppresses liver regeneration through, in part, inhibiting the JAK2/STAT3 pathway. In chronic liver disease, aberrantly-activated hepatic NIK impairs liver regeneration, contributing to liver disease progression.

\section{Experimental Procedures}

Animals. Animal experiments were conducted following the protocols approved by the

279 University of Michigan Institutional Animal Care and Use Committee (IACUC). Mice were 280 housed on a 12-h light-dark cycle and fed a normal chow diet (9\% fat; Lab Diet, St. Louis, MO)

281 or a HFD (60\% fat in calories; D12492, Research Diets, New Brunswick, NJ) ad libitum with 282 free access to water.

283 PHx models. We followed published 2/3 PHx protocols (Mitchell and Willenbring, 2008). 
lateral lobes ( $70 \%$ of the liver) were resected by pedicle ligations. Mice were euthanized 24, 48, or $96 \mathrm{~h}$ after PHx, and tissues were harvested for histological and biochemical analyses. Mice were introperitoneally injected, $12 \mathrm{~h}$ before euthanization, with $\mathrm{BrdU}$ (40 mg/kg body weight, ip) to label proliferating cells. A separate cohort was fed a HFD for 10 weeks prior to PHx. An additional cohort was treated with hepatotoxin 2-acetylaminofluorene (AAF) (10 mg/kg body weight, gavage) daily for 10 days prior to $\mathrm{PHx}$.

Estimation of total liver weight before $\mathrm{PHx}$ : resected liver weight $\div 70 \%$. Calculation of the remnant liver weight after PHx: total liver weight - resected liver weight. Liver weight gains: terminal liver weight - the remnant liver weight. Liver growth rates: liver weight gains normalized to the remnant liver weight after PHx.

Immunostaining. Liver frozen sections were prepared using a Leica cryostat (Leica Biosystems Nussloch GmbH, Nussloch, Germany), fixed in 4\% paraformaldehyde for $30 \mathrm{~min}$, blocked for 3 h with 5\% normal goat serum (Life Technologies) supplemented with 1\% BSA, and incubated with the indicated antibodies at $4^{0} \mathrm{C}$ overnight. The sections were incubated with $\mathrm{Cy} 2$ or $\mathrm{Cy} 3-$ conjugated secondary antibodies.

Cell cultures, transient transfection, and adenoviral transductions. Primary hepatocytes were prepared from mouse liver using type II collagenase (Worthington Biochem, Lakewood, NJ) and grown on William's medium E (Sigma) supplemented with 2\% FBS, 100 units $\mathrm{ml}^{-1}$ penicillin, and $100 \mu \mathrm{g} \mathrm{ml}^{-1}$ streptomycin, and infected with adenoviruses as described previously (Zhou et al., 2009). HEK293 cells were grown at $37^{\circ} \mathrm{C}$ in $5 \% \mathrm{CO}_{2}$ in $\mathrm{DMEM}$ supplemented with $25 \mathrm{mM}$ glucose, $100 \mathrm{U} \mathrm{ml}^{-1}$ penicillin, $100 \mu \mathrm{g} \mathrm{ml}^{-1}$ streptomycin, and $8 \%$ calf serum. For transient transfection, cells were split 16-20 h before transfection. Expression plasmids were mixed with polyethylenimine (Sigma, St. Louis, MO) and introduced into cells. 
The total amount of plasmids was maintained constant by adding empty vectors. Cells were harvested $48 \mathrm{~h}$ after transfection for biochemical analyses.

Immunoprecipitation and immunoblotting. Cells or tissues were homogenized in a L-RIPA lysis buffer (50 mM Tris, pH 7.5, 1\% Nonidet P-40, 150 mM NaCl, 2 mM EGTA, 1 mM $\mathrm{Na}_{3} \mathrm{VO}_{4}, 100 \mathrm{mM} \mathrm{NaF}, 10 \mathrm{mM} \mathrm{Na} \mathrm{P}_{2} \mathrm{O}_{7}, 1 \mathrm{mM}$ benzamidine, $10 \mu \mathrm{g} \mathrm{ml}^{-1}$ aprotinin, $10 \mu \mathrm{g} \mathrm{ml}{ }^{-1}$ leupeptin, $1 \mathrm{mM}$ phenylmethylsulfonyl fluoride). Tissue samples were homogenized in lysis buffer (50 mM Tris, pH 7.5, 1\% Nonidet P-40, 150 mM NaCl, 2 mM EGTA, 1 mM Na $\mathrm{VO}_{4}$, $100 \mathrm{mM} \mathrm{NaF}, 10 \mathrm{mM} \mathrm{Na} 4 \mathrm{P}_{2} \mathrm{O}_{7}, 1 \mathrm{mM}$ benzamidine, $10 \mu \mathrm{g} / \mathrm{ml}$ aprotinin, $10 \mu \mathrm{g} / \mathrm{ml}$ leupeptin; 1 $\mathrm{mM}$ phenylmethylsulfonyl fluoride). Proteins were separated by SDS-PAGE and immunoblotted with the indicated antibodies.

Real-time quantitative PCR (qPCR) and ROS assays. Total RNAs were extracted using TRIzol reagents (Life technologies). Relative mRNA abundance of different genes was measured using SYBR Green PCR Master Mix (Life Technologies, 4367659). Liver lysates were mixed with a dichlorofluorescein diacetate fluorescent (DCF, Sigma, D6883) probe $(5 \mu \mathrm{M})$ for $1 \mathrm{~h}$ at $37^{0} \mathrm{C}$. DCF fluorescence was measured using a BioTek Synergy 2 Multi-Mode Microplate Reader (485 $\mathrm{nm}$ excitation and $527 \mathrm{~nm}$ emission).

Statistical Analysis. Data were presented as means \pm sem. Differences between two groups was analyzed using two-tailed Student's t tests. $\mathrm{P}<0.05$ was considered statistically significant.

\section{Author Contributions}

YX, AST, LR: Study concept and design; YX, AST, FW, HS, YL, MJC: acquisition of data; YX, AST, LR: drafting of the manuscript; YS, BMO, LY: critical revision of the manuscript for important intellectual content. 
332 We thank Drs. Lin Jiang, Liang Sheng, Chengxin Sun, and Lei Yin and Michelle Jin for 333 assistance and discussion. This study was supported by grants DK091591, DK114220 (LR) and 334 DK47918 (MBO) from the National Institutes of Health (NIH), fellowship \#2013/07313-4 from 335 São Paulo Research Foundation (FAPESP) (AST), and grant 81420108006 (YL) from National 336 Natural Science Foundation of China. This work utilized the cores supported by the Michigan 337 Diabetes Research and Training Center (NIH DK20572), the University of Michigan's Cancer 338 Center (NIH CA46592), the University of Michigan Nathan Shock Center (NIH P30AG013283), 339 and the University of Michigan Gut Peptide Research Center (NIH DK34933).

\section{References} by Restoring GH/EGFR Pathway Deficiency. Endocrinology 155, 2545-2554.

346 Cressman, D.E., Greenbaum, L.E., DeAngelis, R.A., Ciliberto, G., Furth, E.E., Poli, V., and Taub, R. (1996).

347 Liver failure and defective hepatocyte regeneration in interleukin-6-deficient mice. Science 274, 1379-

3481383.

349 Inaba, Y., Furutani, T., Kimura, K., Watanabe, H., Haga, S., Kido, Y., Matsumoto, M., Yamamoto, Y., 350 Harada, K., Kaneko, S., et al. (2015). Growth arrest and DNA damage-inducible 34 regulates liver 351 regeneration in hepatic steatosis in mice. Hepatology 61, 1343-1356. 
Jiang, B., Shen, H., Chen, Z., Yin, L., Zan, L., and Rui, L. (2015). Carboxyl Terminus of HSC70-interacting

Protein (CHIP) Down-regulates NF-kappaB-inducing Kinase (NIK) and Suppresses NIK-induced Liver

Injury. The Journal of biological chemistry 290, 11704-11714.

Laishes, B.A., and Rolfe, P.B. (1981). Search for endogenous liver colony-forming units in F344 rats given

1741.

Liu, B., Xia, X., Zhu, F., Park, E., Carbajal, S., Kiguchi, K., DiGiovanni, J., Fischer, S.M., and Hu, Y. (2008).

IKKalpha is required to maintain skin homeostasis and prevent skin cancer. Cancer Cell 14, 212-225.

Michalopoulos, G.K. (2013). Principles of liver regeneration and growth homeostasis. Compr Physiol 3,

485-513.

Michalopoulos, G.K. (2017). Hepatostat: Liver regeneration and normal liver tissue maintenance.

364 Mitchell, C., and Willenbring, H. (2008). A reproducible and well-tolerated method for 2/3 partial 365 hepatectomy in mice. Nat Protoc 3, 1167-1170.

366 Miyaoka, Y., Ebato, K., Kato, H., Arakawa, S., Shimizu, S., and Miyajima, A. (2012). Hypertrophy and

367 unconventional cell division of hepatocytes underlie liver regeneration. Curr Biol 22, 1166-1175.

368 Pauta, M., Rotllan, N., Fernandez-Hernando, A., Langhi, C., Ribera, J., Lu, M., Boix, L., Bruix, J., Jimenez,

369 W., Suarez, Y., et al. (2016). Akt-mediated foxo1 inhibition is required for liver regeneration. Hepatology

$370 \quad 63,1660-1674$.

371 Richardson, M.M., Jonsson, J.R., Powell, E.E., Brunt, E.M., Neuschwander-Tetri, B.A., Bhathal, P.S., Dixon,

372 J.B., Weltman, M.D., Tilg, H., Moschen, A.R., et al. (2007). Progressive fibrosis in nonalcoholic

373 steatohepatitis: association with altered regeneration and a ductular reaction. Gastroenterology 133,

$37480-90$. 
Riehle, K.J., Campbell, J.S., McMahan, R.S., Johnson, M.M., Beyer, R.P., Bammler, T.K., and Fausto, N. (2008). Regulation of liver regeneration and hepatocarcinogenesis by suppressor of cytokine signaling 3. J Exp Med 205, 91-103.

Rui, L. (2014). Energy metabolism in the liver. Compr Physiol 4, 177-197.

Rui, L., and Carter-Su, C. (1999). Identification of SH2-bbeta as a potent cytoplasmic activator of the tyrosine kinase Janus kinase 2. Proc Natl Acad Sci U S A 96, 7172-7177.

Sancho-Bru, P., Altamirano, J., Rodrigo-Torres, D., Coll, M., Millan, C., Jose Lozano, J., Miquel, R., Arroyo, V., Caballeria, J., Gines, P., et al. (2012). Liver progenitor cell markers correlate with liver damage and predict short-term mortality in patients with alcoholic hepatitis. Hepatology 55, 1931-1941.

Shen, H., Sheng, L., Chen, Z., Jiang, L., Su, H., Yin, L., Omary, M.B., and Rui, L. (2014). Mouse hepatocyte overexpression of NF-kappaB-inducing kinase (NIK) triggers fatal macrophage-dependent liver injury and fibrosis. Hepatology 60, 2065-2076.

Shen, H., Sheng, L., Xiong, Y., Kim, Y.H., Jiang, L., Chen, Z., Liu, Y., Pyaram, K., Chang, C.H., and Rui, L. (2017). Thymic NF-kappaB-inducing Kinase (NIK) Regulates CD4+ T Cell-elicited Liver Injury and Fibrosis in Mice. J Hepatol.

Sheng, L., Zhou, Y., Chen, Z., Ren, D., Cho, K.W., Jiang, L., Shen, H., Sasaki, Y., and Rui, L. (2012). NFkappaB-inducing kinase (NIK) promotes hyperglycemia and glucose intolerance in obesity by augmenting glucagon action. Nat Med 18, 943-949.

Shi, S.Y., Schroer, S.A., Luk, C.T., Kim, M.J., Dodington, D.W., Lin, L., Sivasubramaniyam, T., Cai, E.P., Lu, S.Y., Wagner, K.U., et al. (2017). Janus kinase 2 (JAK2) Dissociates Hepatosteatosis from Hepatocellular Carcinoma in Mice. The Journal of biological chemistry.

Sun, S.C. (2012). The noncanonical NF-kappaB pathway. Immunol Rev 246, 125-140.

Wang, H., Lafdil, F., Kong, X., and Gao, B. (2011). Signal transducer and activator of transcription 3 in liver diseases: a novel therapeutic target. Int J Biol Sci 7, 536-550. 
399 Wuestefeld, T., Pesic, M., Rudalska, R., Dauch, D., Longerich, T., Kang, T.W., Yevsa, T., Heinzmann, F.,

400 Hoenicke, L., Hohmeyer, A., et al. (2013). A Direct In Vivo RNAi Screen Identifies MKK4 as a Key

401 Regulator of Liver Regeneration. Cell 153, 389-401.

402 Xiao, G., Harhaj, E.W., and Sun, S.C. (2001). NF-kappaB-inducing kinase regulates the processing of NF-

403 kappaB2 p100. Mol Cell 7, 401-409.

404 Zhou, Y., Jiang, L., and Rui, L. (2009). Identification of MUP1 as a regulator for glucose and lipid

405 metabolism in mice. The Journal of biological chemistry 284, 11152-11159.

406

407

408 

proliferation. $N I K^{\text {floxfflox }}(\mathrm{n}=7)$ and $N I K^{\Delta h e p}(\mathrm{n}=7)$ male mice $(8$ weeks) were subjected to PHx, and livers were harvested $48 \mathrm{~h}$ or $96 \mathrm{~h}$ later. (A) Representative immunostaining of liver sections

413 (48 h after PHx) with anti-Ki67. (B) Ki67 ${ }^{+}$cells were counted and normalized to total DAPI cells. (C) Representative immunostaining of liver sections (48 h after PHx) with anti-BrdU antibodies. (D-E) Representative images of liver sections (48 h after PHx) costained with anti-

416 Ki67 and anti-HNF4 $\alpha$ antibodies (D) or anti-Ki67 and anti-F4/80 antibodies (E). (F)

$417 \mathrm{Ki}^{+} \mathrm{HNF} 4 \alpha^{+}$and $\mathrm{Ki}^{+} 7^{+} \mathrm{F} 4 / 80^{+}$cells were counted and normalized to total $\mathrm{Ki} 67^{+}$cells. $(\mathbf{G})$

418 Liver cell death were assessed $48 \mathrm{~h}$ after PHx using TUNEL reagents. (H) Plasma ALT levels.

419 (I) Liver growth rates within $48 \mathrm{~h}$ after PHx. Data were statistically analyzed with two-tailed

420 Student's t test, and presented as mean \pm SEM. * ${ }^{*}<0.05$.

421

422

423

424

425

426

427

428

429

\section{Figure 2. Hepatic NIK deficiency upregulates cyclin D1 without altering NF-kB1, Akt, and} MAPK pathways in the liver. $N I K^{\text {floxflox }}$ and $N I K^{\Delta h e p}$ male mice ( 8 weeks) were subjected to PHx. (A-B) Liver extracts were immunoblotted with anti-cyclin D1 antibody (48 h after PHx). Cyclin D1 levels were quantified and normalized to $\alpha$-tubulin levels $\left(N I K^{\text {floxflox }}: \mathrm{n}=7, N I K^{\Delta h e p}\right.$ : $\mathrm{n}=7$ ). (C) Liver extracts were immunoblotted with the indicated antibodies ( $4 \mathrm{~h}$ after PHx). (D) Liver ROS levels $48 \mathrm{~h}$ after PHx (normalized to liver weight). NIK floxflox: $\mathrm{n}=4, N I K^{\text {4hep }}: \mathrm{n}=4$. (E) Liver cytokine expression was measured by qPCR and normalized to 36B4 expression ( $48 \mathrm{~h}$ after PHx). NIK floxflox: $\mathrm{n}=5, N I K^{\text {Uhep }}: \mathrm{n}=5$. Data were statistically analyzed with two-tailed Student's t test, and presented as mean \pm SEM. $* \mathrm{p}<0.05$.

Figure 3. NIK inhibits the JAK2/STAT3 pathway. (A) Liver extracts were prepared from NIK $K^{\text {floxflox }}$ and NIK ${ }^{\text {Shep }}$ male $4 \mathrm{~h}$ after PHx and immunoblotted with anti-phospho-JAK2 and anti- 
phospho-STAT3 antibodies. Phosphorylation of JAK2 (pTyr1007/1008) and STAT3 (pTyr705) was normalized to total JAK2 and STAT3 levels, respectively. (B) STAT3 and JAK2 were coexpressed with or without NIK in HEK293 cells. Cell extracts were immunoblotted with the indicated antibodies. (C) NIK was coexpressed with JAK2 in HEK293 cells. Cell extracts were immunoprecipitated (IP) and immunoblotted with the indicated antibodies. (D) Mouse primary hepatocytes were transduced with NIK or $\beta$-gal adenoviral vectors and stimulated with IL6 (10 ng/ml). Cell extracts were immunoblotted with the indicated antibodies. Data were statistically analyzed with two-tailed Student's $t$ test, and presented as mean \pm SEM. ${ }^{*} \mathrm{p}<0.05$.

\section{Figure 4. Hepatocyte-specific deletion of $I K K \alpha$ accelerates hepatocyte reparative}

proliferation. (A) Tissue extracts were immunoblotted with anti-IKK $\alpha$ or anti- $\alpha$-tubulin antibodies. (B-F) $I K K \alpha^{\text {floxfllox }}(\mathrm{n}=6)$ and $I K K \alpha^{\text {thep }}(\mathrm{n}=6)$ male littermates were subjected to PHx, and livers were harvested 48 h later. (B) Liver sections were immunostained with anti-Ki67 antibody, and $\mathrm{Ki}^{+} 7^{+}$cells were counted and normalized to total DAPI ${ }^{+}$cells. $(\mathbf{C})$ Representative images of liver sections costained with anti-Ki67 and anti-HNF4 $\alpha$ antibodies. (D) Liver cyclin D1 was measured by immunoblotting (normalized to $\alpha$-tubulin levels). (E) TUNEL-positive cells in liver sections. (F) Liver growth rates within $48 \mathrm{~h}$ after PHx. Data were statistically analyzed with two-tailed Student's t test, and presented as mean \pm SEM. $* \mathrm{p}<0.05$.

Figure 5. IKKa inhibits the JAK2/STAT3 pathway. (A-B) Liver extracts were prepared $4 \mathrm{~h}$ after PHx and immunoblotted with anti-phospho-JAK2 and anti-phospho-STAT3 antibodies. Phosphorylation of JAK2 (pTyr1007/1008) and STAT3 (pTyr705) was normalized to total JAK2 and STAT3 levels, respectively. IKKo ${ }^{\text {floxflox }}: \mathrm{n}=5, I K K \alpha^{\text {Shep }}: \mathrm{n}=5$. (C) STAT3 and JAK2 were coexpressed with IKK $\alpha$ in HEK293 cells. Cell extracts were immunoblotted with the indicated antibodies. (D) IKK $\alpha$ and JAK2 were coexpressed in HEK293 cells. Cell extracts were 
455

456

457

458

459

460

461

462

463

464

465

466

467

468

469

470

471

472

473

474

475

476

477

immunoprecipitated (IP) and immunoblotted with the indicated antibodies. Data were

statistically analyzed with two-tailed Student's $t$ test, and presented as mean \pm SEM. ${ }^{*} p<0.05$.

Figure 6. Hepatocyte-specific deletion of NIK reverses AAF-induced impairment in hepatocyte reparative proliferation. (A) C57BL/6 males (8 weeks) were treated with PBS or AAF (10 mg/kg body weight, gavage) daily for 10 days. NF-kB2 p52 in liver extracts was immunoblotted with anti-NF-kB2 antibody (normalized to $\alpha$-tubulin levels). PBS: n=4, AAF: $\mathrm{n}=4$. (B-G) $N I K^{\text {flox/flox }}$ and $N I K^{\text {Shep }}$ males were treated with PBS or AAF (10 $\mathrm{mg} / \mathrm{kg}$ body weight) for 10 days and then subjected to PHx. Livers were harvested 48 h later. (B) Representative immunostaining of liver sections with anti-Ki67 antibody. (C) Baseline Ki67 ${ }^{+}$cell number in resected liver sections obtained from PHx. $N I K^{\text {floxflox }}: \mathrm{n}=3, N I K^{\Delta h e p}: \mathrm{n}=3$. (D) $\mathrm{Ki}^{+} 7^{+}$cell number in liver sections (normalized to $\mathrm{DAPI}^{+}$cells). PBS;NIK flox/flox $: \mathrm{n}=3, \mathrm{AAF} ; N I K^{\text {floxfflox }}$ : $\mathrm{n}=5$, AAF;NIK ${ }^{\text {Ahep }}: \mathrm{n}=5$. (E) Plasma ALT levels. NIK ${ }^{\text {floxfflox }}: \mathrm{n}=3, N I K^{\text {Ahep }}: \mathrm{n}=4$. (F) Liver regeneration rates within $48 \mathrm{~h}$ after PHx. NIK floxflox $: \mathrm{n}=5, N I K^{\Delta h e p}: \mathrm{n}=5$. $(\mathbf{G})$ Liver extracts were immunoblotted with the indicated antibodies. Data were statistically analyzed with two-tailed Student's $t$ test, and presented as mean \pm SEM. ${ }^{*} p<0.05$.

Figure 7. Hepatic NIK deficiency corrects impaired hepatocyte reparative proliferation in mice with NAFLD. (A-B) C57BL/6 males (8 weeks) were fed a normal chow diet $(n=5)$ or a HFD ( $n=5)$ for 10 weeks. (A) Liver TAG levels (normalized to liver weight). (B) NF-kB2 p52 in liver extracts was immunoblotted with anti-NF-kB2 antibody (normalized to $\alpha$-tubulin levels). (C-H) $N I K^{f l o x / f l o x}$ and $N I K^{\Delta h e p}$ males were fed a HFD for 10 weeks followed by PHx, and livers were harvested $48 \mathrm{~h}$ after PHx. (C) Representative immunostaining of liver sections with antiKi67 antibody. (D) Baseline $\mathrm{Ki}^{+} 7^{+}$cell number in resected liver sections obtained from PHx. $N I K^{\text {floxflox }}: \mathrm{n}=4$, NIK $^{\text {thep }}: \mathrm{n}=4$. (E) Liver Ki67 ${ }^{+}$cell number (normalized to DAPI ${ }^{+}$cells). 
478 Chow;NIK flox/flox: n=3, HFD;NIK flox/flox: n=5, HFD;NIK ${ }^{\Delta h e p}: \mathrm{n=5}$. (F) Liver growth rates within 48

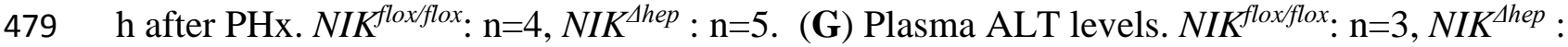

$480 \mathrm{n}=4$. (H) Liver extracts were immunoblotted with the indicated antibodies. Data were statistically

481 analyzed with two-tailed Student's t test, and presented as mean \pm SEM. ${ }^{*} \mathrm{p}<0.05$. 
Fig. 1

A

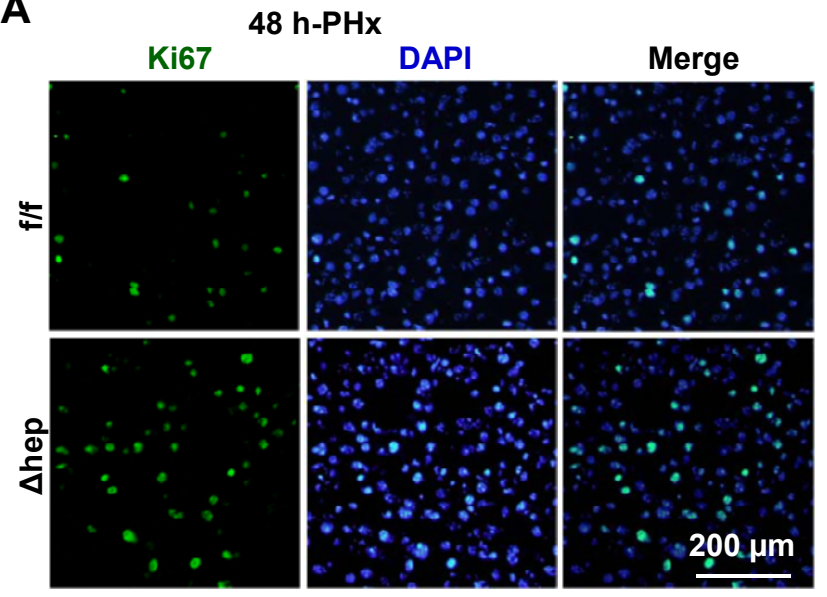

B

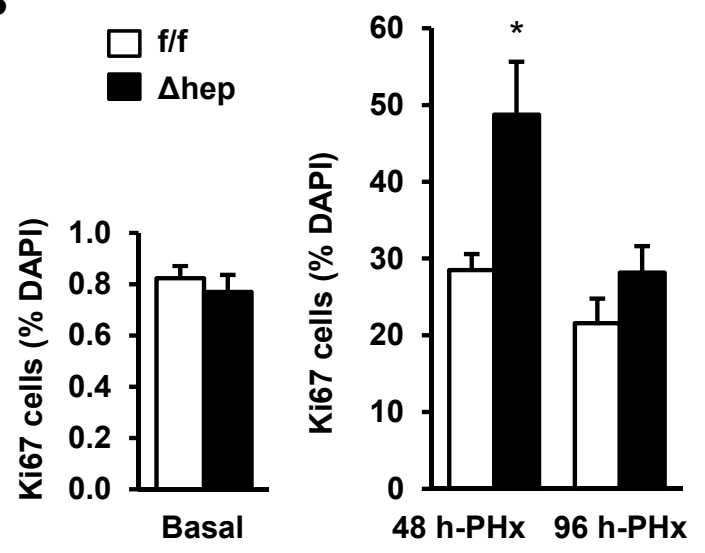

C
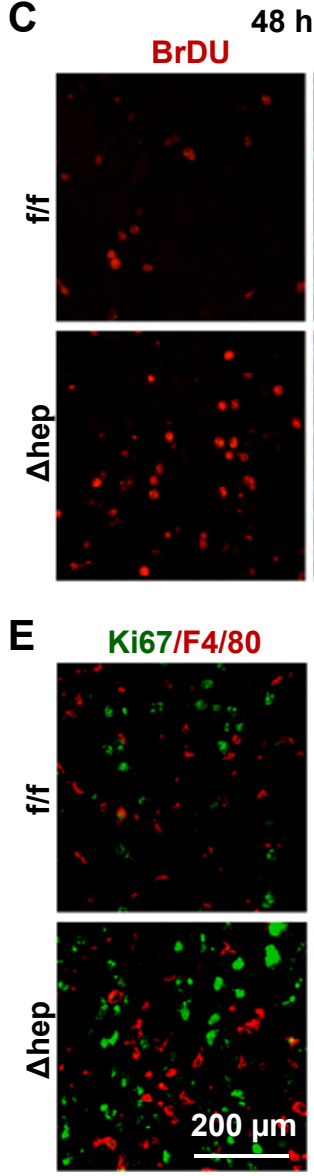

DAPI

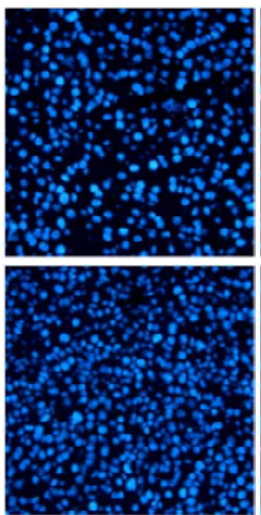

$\mathbf{F}$
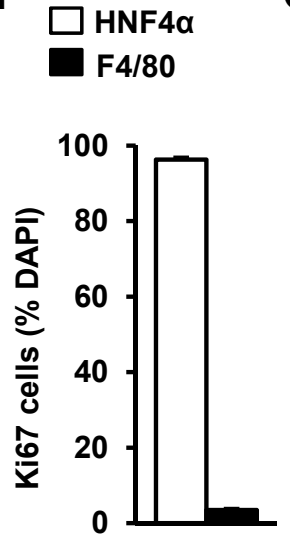

Merge
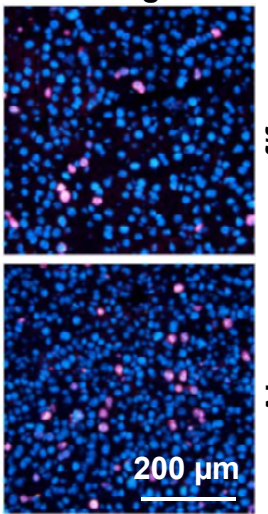

G
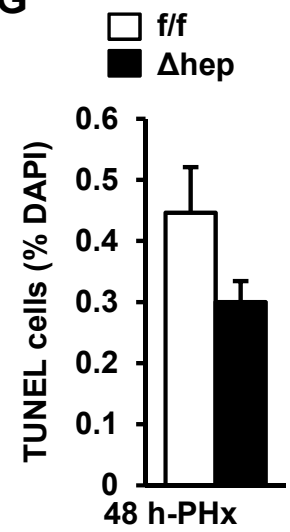

D 48 h-PHx

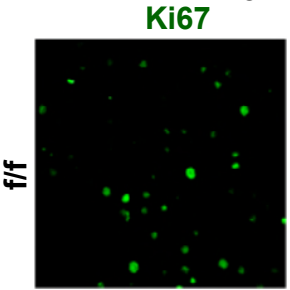

HNF4a

Merge
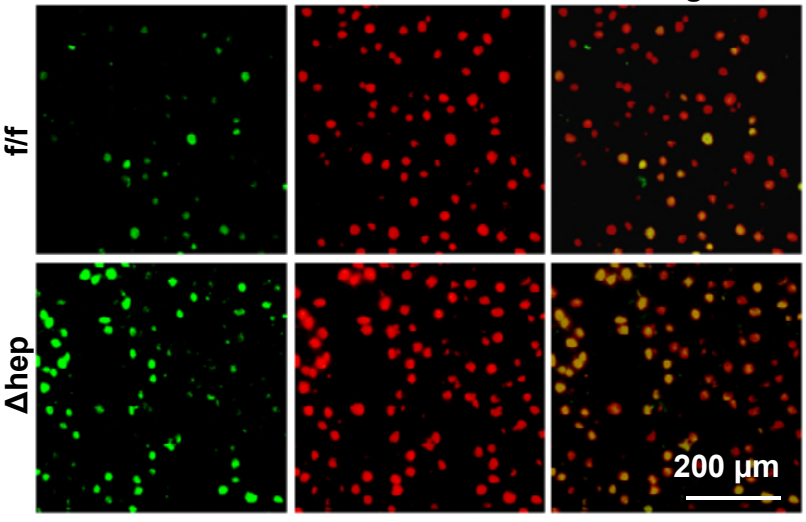

H

$\square$ f/f

I
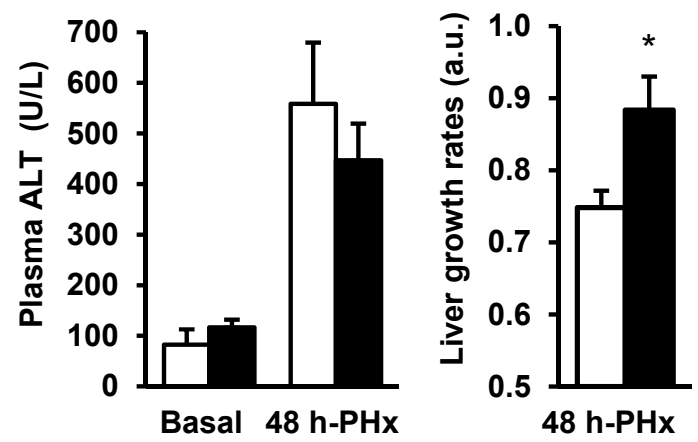
Fig. 2

A

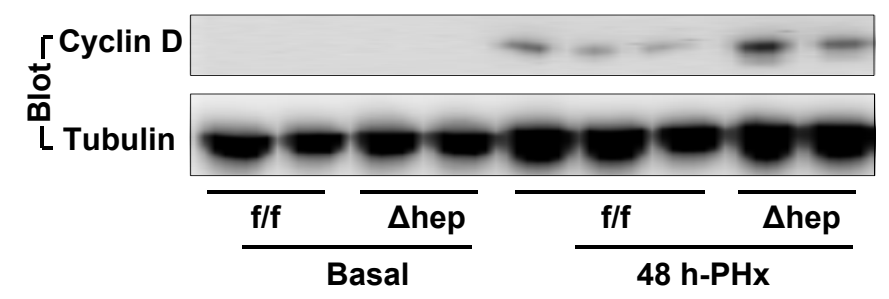

B

C

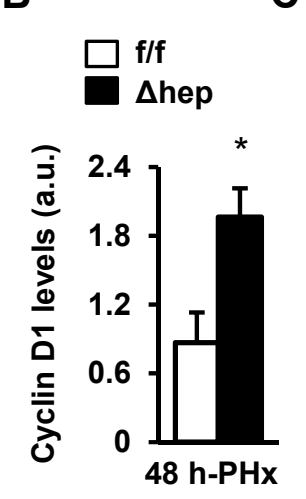

D $\square_{\Delta \text { hep }}^{\text {f/f }}$
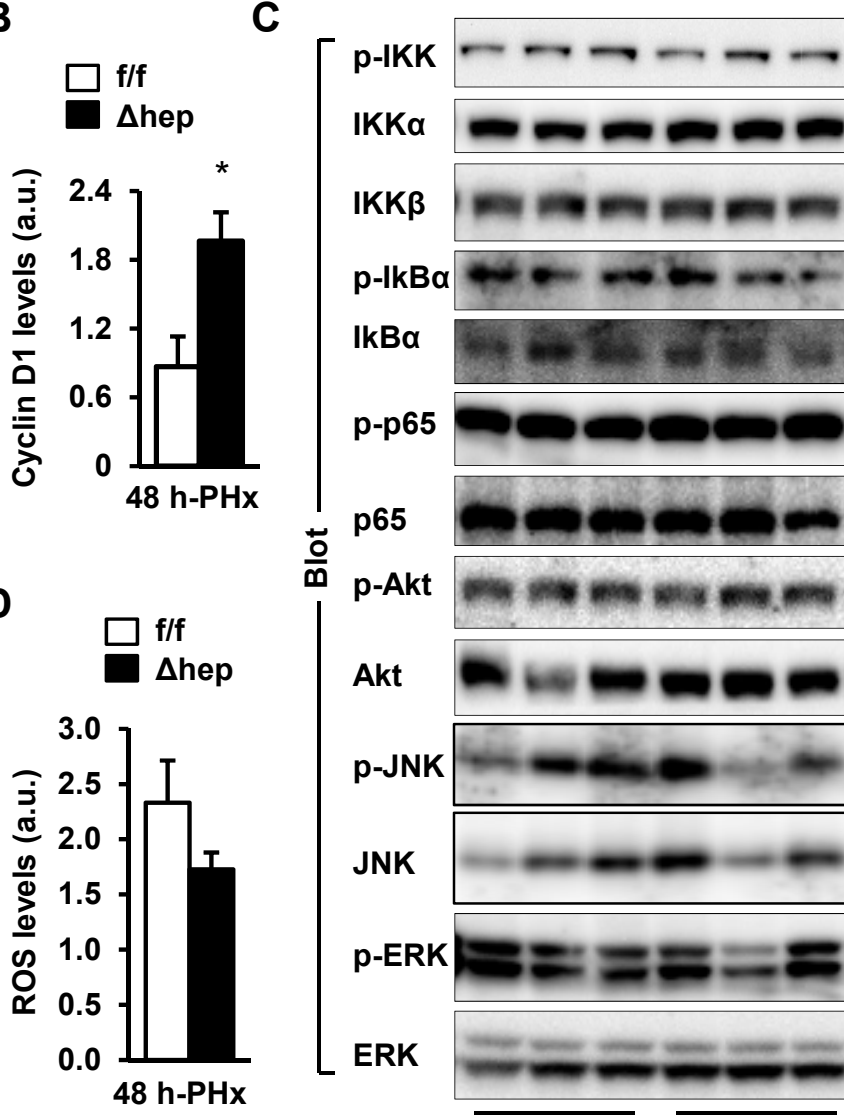

흠

p65

Akt

Akt

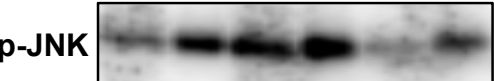

JNK $-m-m$

p-ERK

ERK

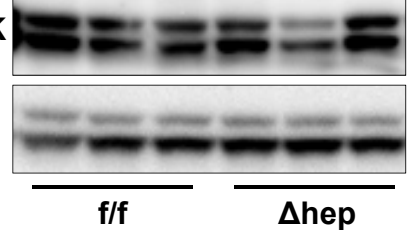

$\mathbf{E}$

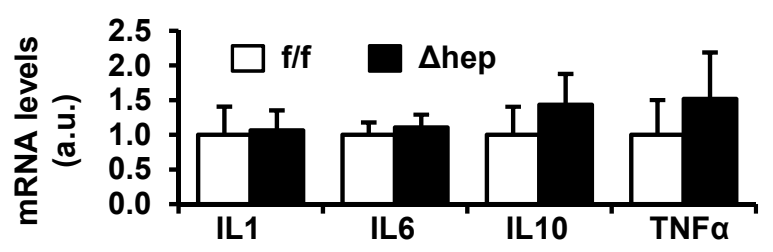


Fig. 3

A

C
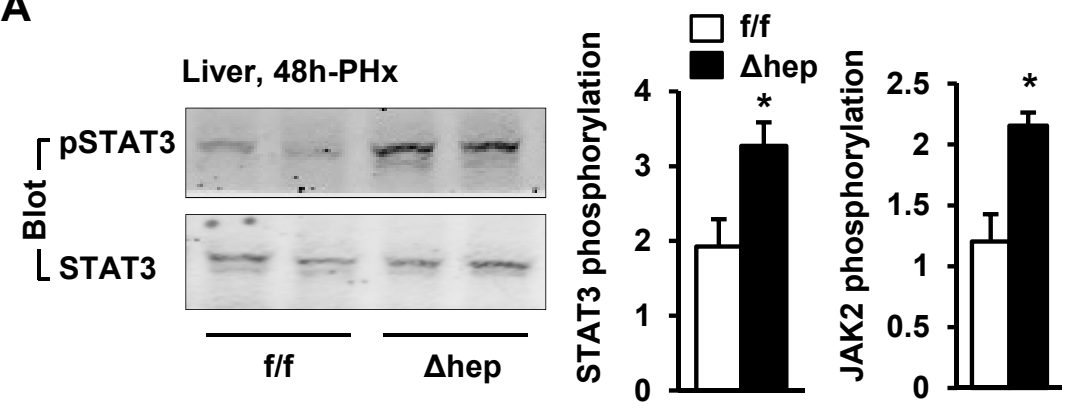

D
B

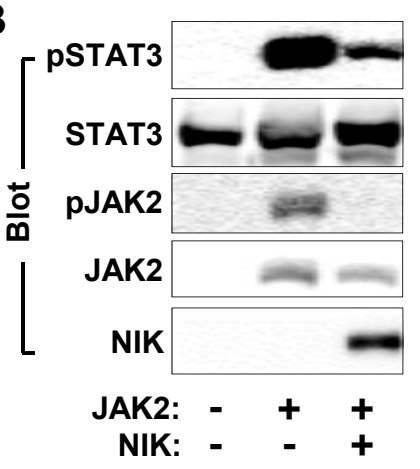

IP: Flag-NIK

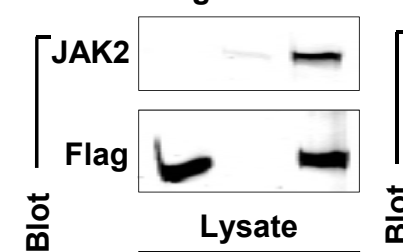

क्ष Lysate

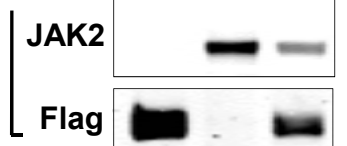

JAK2: -++ NIK: +-+
IP: Flag-JAK2
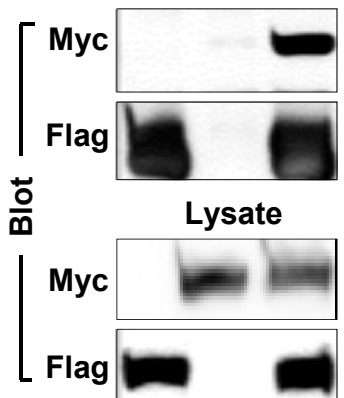

JAK2: - + + NIK: + - +

\section{Primary hepatocytes}
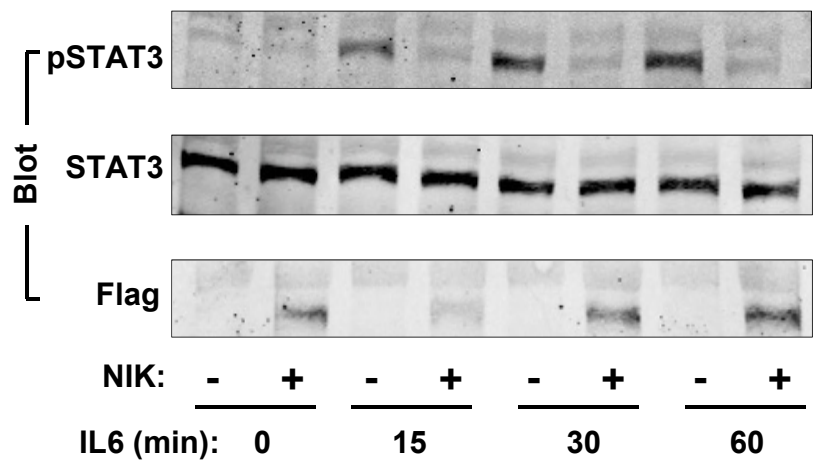
Fig. 4

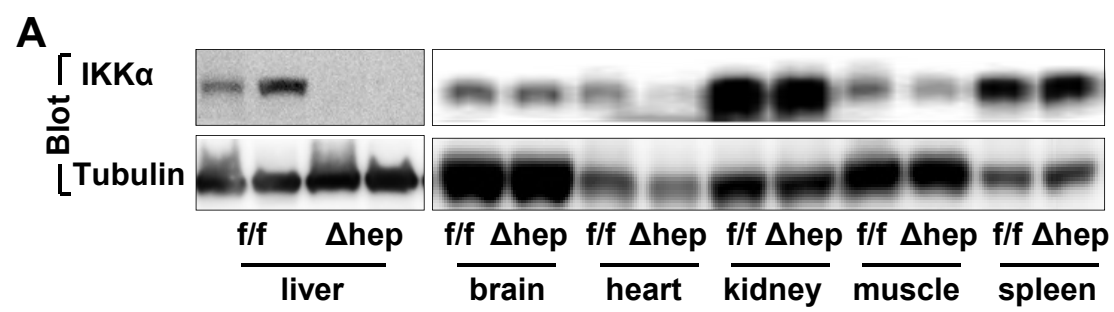

B
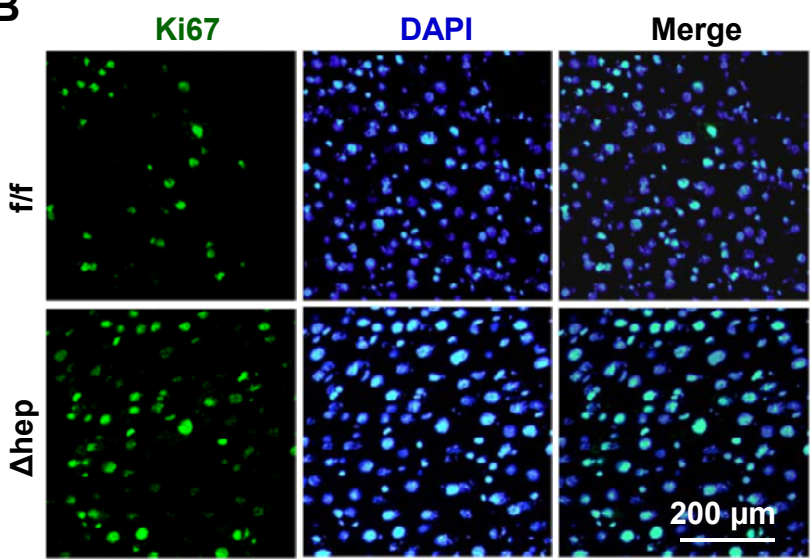

C

Ki67

HNF4a
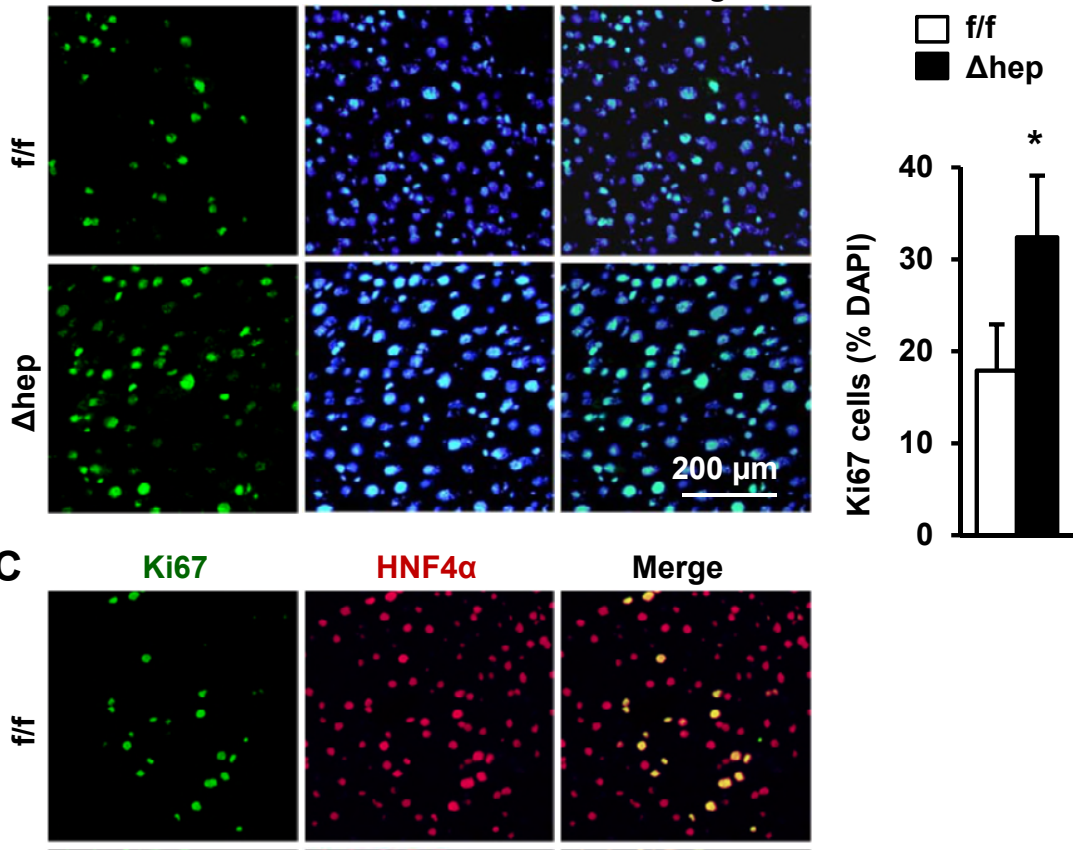

Merge
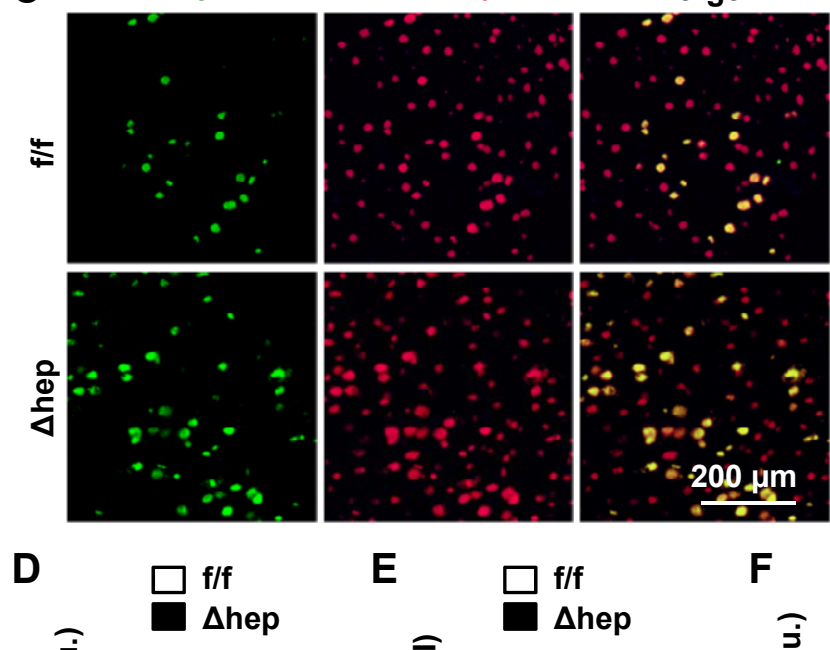

$\mathbf{E}$
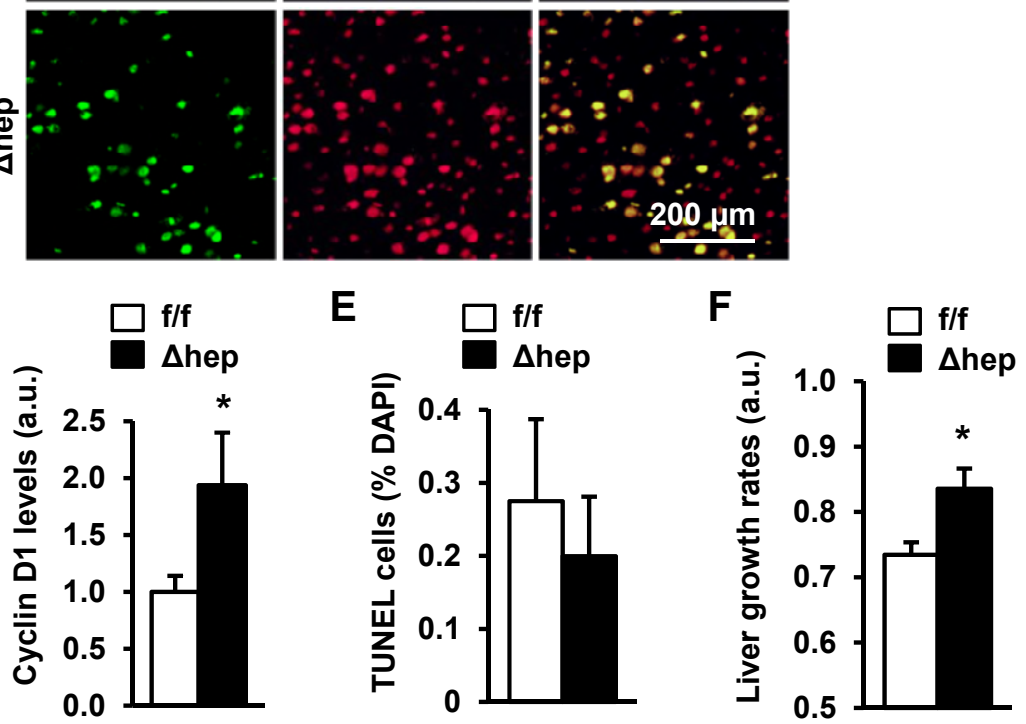
Fig. 5

A

Liver, 4 h-PHx

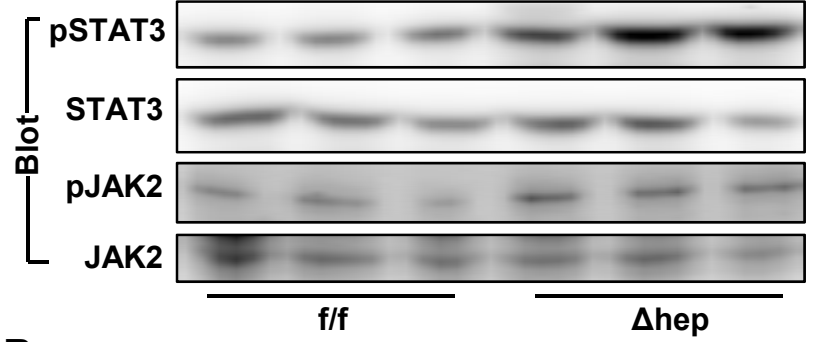

B

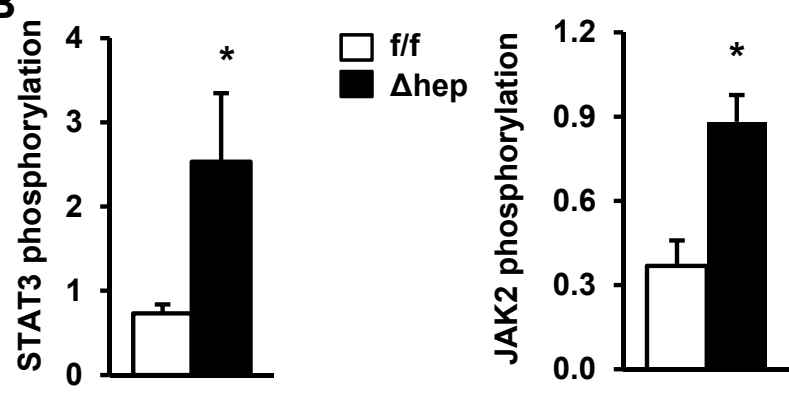

C Lysate

D IP: Flag-IKKa
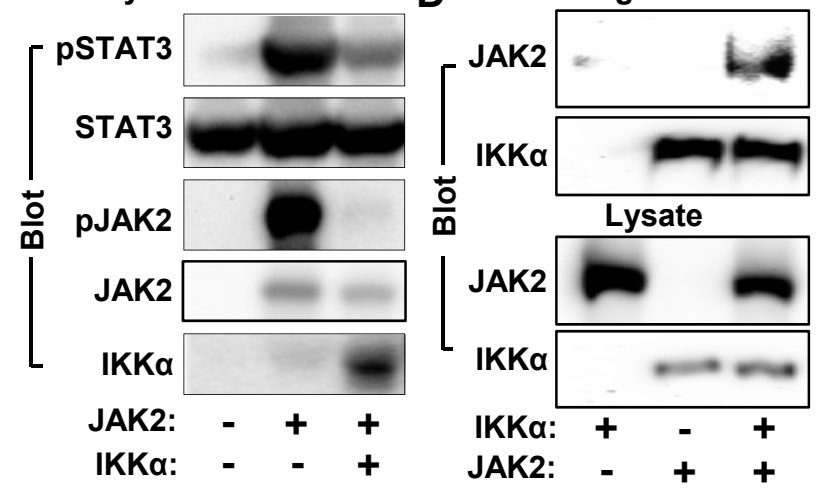
Fig. 6

A
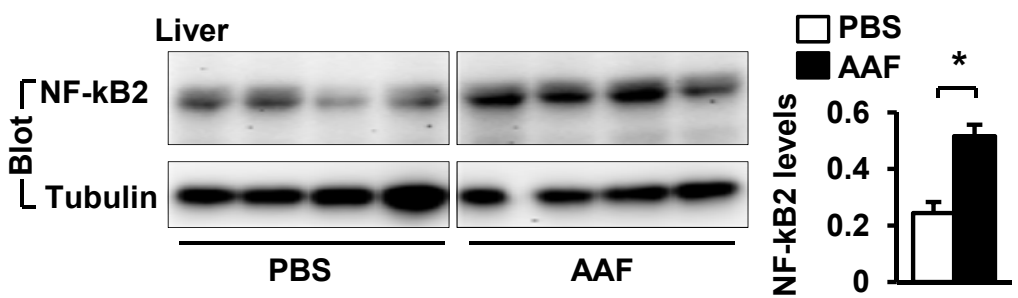

B

Ki67

DAPI
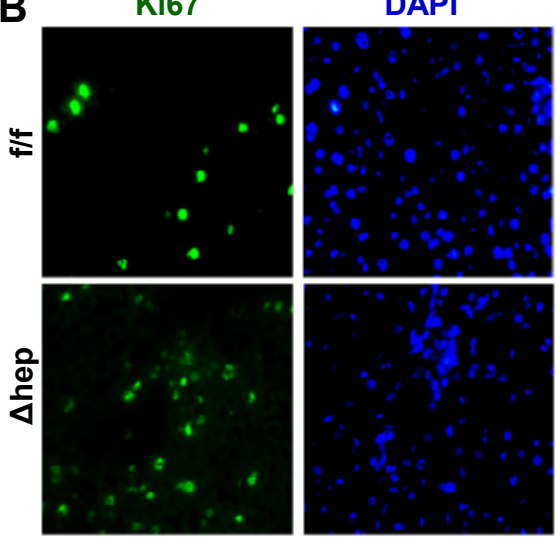

Merge

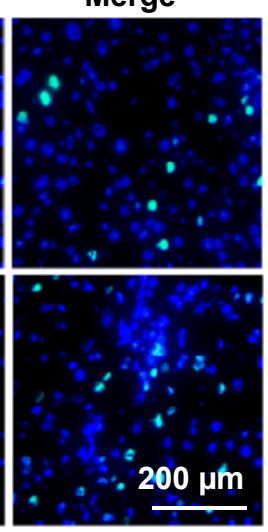

C $\square \mathrm{f} / \mathrm{f}$ $\square$ uhep

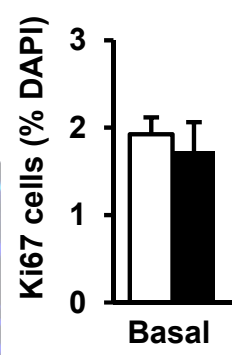

D

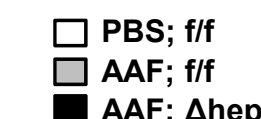

E

F
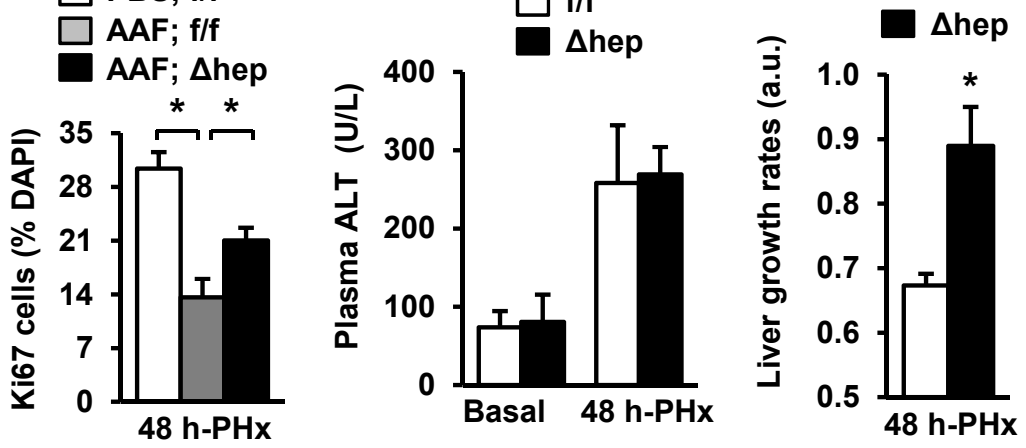

G

Liver, AAF

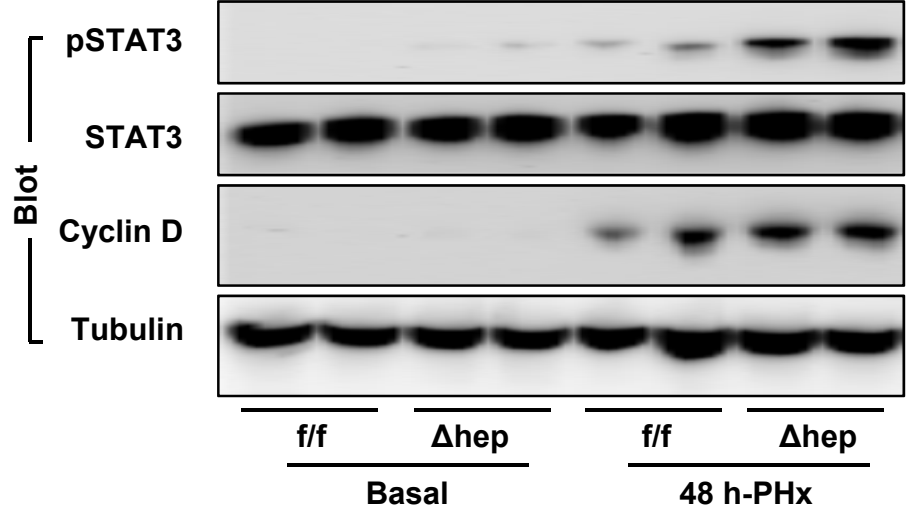


Fig. 7

A

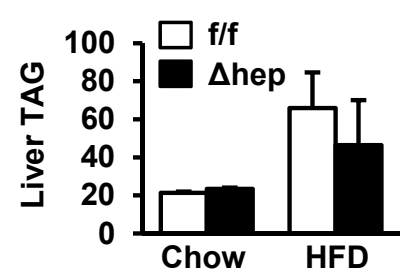

C
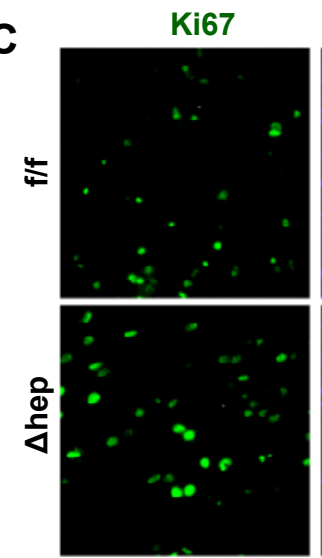

$\mathbf{E}$
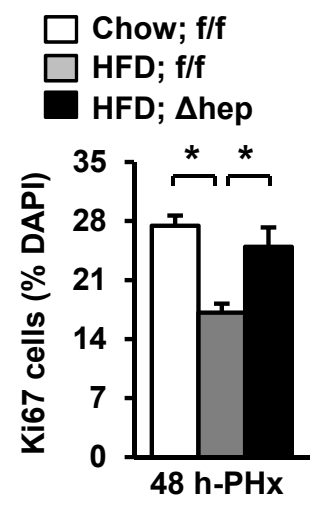

$\mathbf{F}$
B
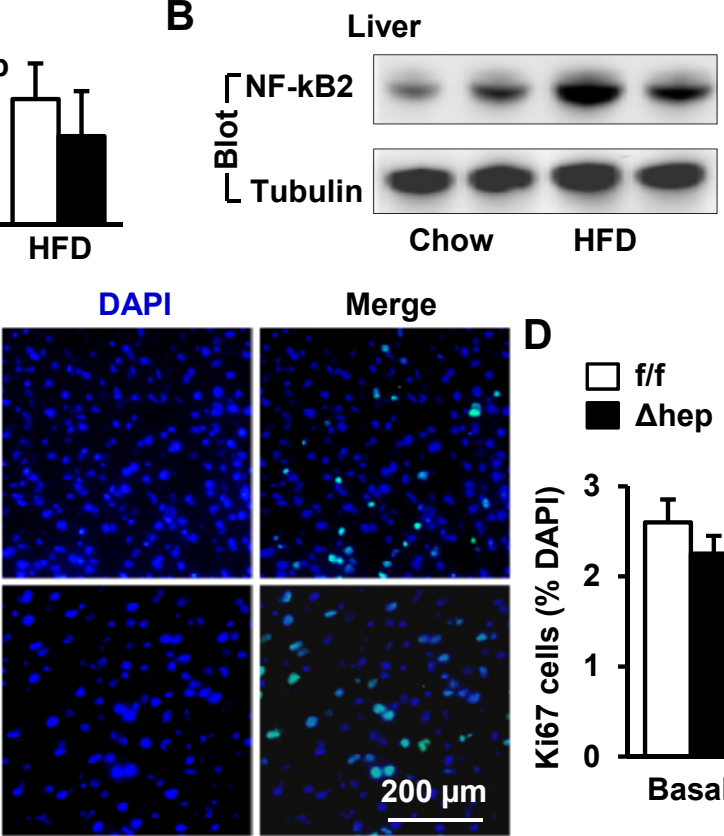

$\square$ ahep
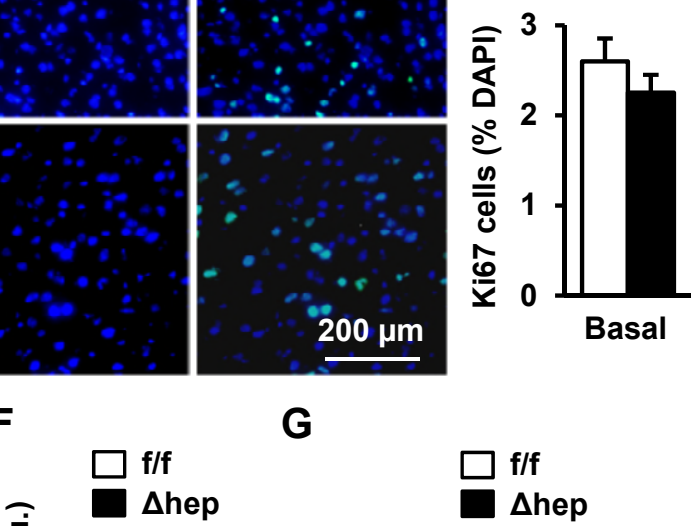

G
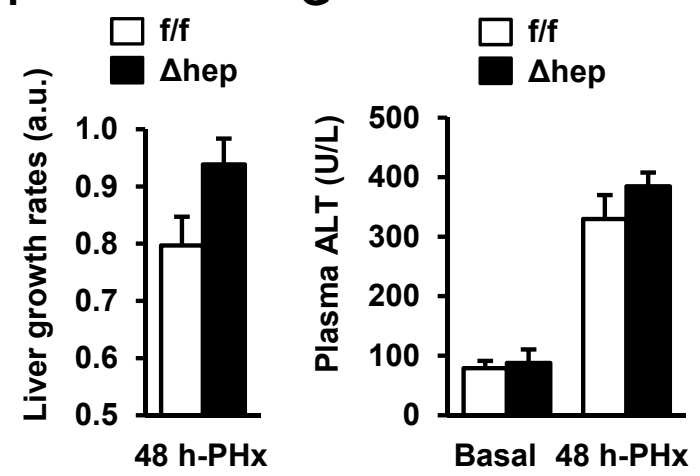

H

Liver, HFD

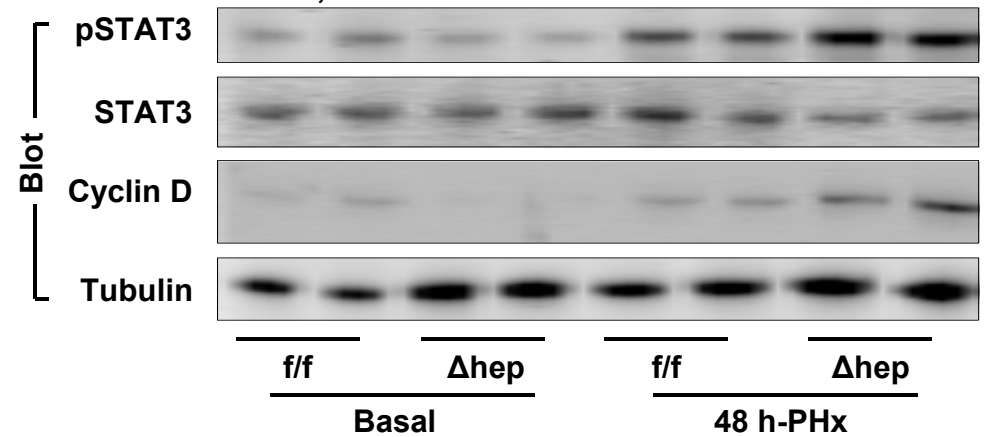

